\title{
Inhibition of Diphenol oxidase activity of strawberry (Fragaria sp) Using L-cysteine and L-glycine
}

\author{
Shahriar Saeidian* \\ Department of Biology, Payame Noor University Iran \\ *E-mail address: saeedyan@pnu.ac.ir
}

\begin{abstract}
L-glycine and L-cysteine exhibit, strong inhibition of partial purified DIPHENOL OXIDASE at strawberry. The concentration of L-glycine inhibiting Diphenol oxidase activity by $50 \%$ (IC50) was 0.5 and $0.4 \mathrm{mM}$ at $\mathrm{pH} 6.7$ and 8 , respectively. The inhibition of partial purified Diphenol oxidase activity is $\mathrm{pH}$ and inhibitor dependent. Kinetic studies indicate that L-glycine is a uncompetetive inhibitor and L-cysteine is competitive and noncompetitive inhibitor of Diphenol oxidase activity. $\mathrm{V}_{\max }$ and $\mathrm{Km}$ for catechol oxidation at $\mathrm{pH} 6.7$ and in presence of L-glycine (1.4M) was $0.09 \Delta \mathrm{A} \mathrm{min}{ }^{-1}$ and $10 \mathrm{mM}$. $\mathrm{V}_{\max }$ for catechol oxidation at $\mathrm{pH} 8$ and in absence of L-glycine was $0.09 \Delta \mathrm{A} \mathrm{min}{ }^{-1}$, with a $\mathrm{Km}$ of $3.5 \mathrm{mM}$. Kinetics parameters indicated the highest catalytic efficiency ( units $\mathrm{mg}^{-1}$ prot $\mathrm{mM}^{-1}$ ) with catechol and L-glycine at $\mathrm{pH} 8: 4$, then with L-cystein at $\mathrm{pH} 8: 1.7$, Lglycine at $\mathrm{pH}$ 6.7: 1.4 and L-cystein at $\mathrm{pH}$ 6.7: 0.25.
\end{abstract}

Keyword: Inhibition; L-cysteine; polyphenol oxidase; strawberry; Crataegus spp

\section{INTRODUCTION}

Many vegetables and fruits become discolored during storage or processing, an action mediated by the enzyme polyphenol oxidase [ Broothaerts et al., 2000]. Diphenol oxidase (tyrosinase, EC 1-14-18-1) is a copper-containing enzyme that is widespread in plants, synthesised early in tissue development and stored in chloroplasts [Van Gelder et al., 1997]. The enzyme is widely distributed in a multitude of organisms from bacteria to mammals [Robb., 1984]. Enzymatic browning is the main function of polyphenol oxidase in fruits and vegetables, and it is often undesirable and responsible for unpleasant sensory qualities and reduction in nutrient quality [Sanchez-Amat et al., 1997]. When cell membrane integrity is disrupted, phenolic substrates encounter the enzyme and are converted to o-quinones in a two-step process of hydroxylation of monophenols to diphenols (monophenolase activity), followed by oxidation of diphenols to o-quinones (Diphenol oxidase activity) [Espin et al., 1998]. Diphenol oxidase has been implicated in the formation of pigments, oxygen scavenging [Trebst et al., 1995] and defense mechanism against plant pathogens,[ Mohammadi et al., 2002] and herbivory insects [Constabel et al., 2000]. Phenolic compounds serve as precursors in the formation of physical polyphenolic barriers, limiting pathogen translocation. The quinones formed by Diphenol oxidases can bind plant proteins, reducing protein digestibility and their nutritive value to herbivores [Ryan., 2000]. On the other hand, the oxidation of phenolic substrates by Diphenol oxidase is thought to be the 
major cause of the brown coloration of many fruits and vegetables during ripening, handling, storage and processing.

\section{MATERIALS AND METHODS}

The strawberry used in this study were obtained from Kurdistan of Iran and frozen at $-25{ }^{\circ} \mathrm{C}$ until used. Catechol, polyvinylpyrolidone (PVPP), catechol, tyrosine were purchased from Merck (Darmstadt, Germany). Acetone, ammonium sulphate, L-cysteine, kojic acid, L-glycine, polyethylene glycol (PEG), phenylmethylsulfonyl fluoride (PMSF), cellulose membrane $(76 \times 49 \mathrm{~mm})$ and DEAE-cellulose were purchased from Sigma-Aldrich (St. Louis, USA). All chemicals were of analytical grade.

\subsection{Enzyme Extraction and Ion Exchange Chromatography}

500 grams of strawberry were homogenized in $250 \mathrm{~mL}$ of $0.1 \mathrm{M}$ phosphate buffer $(\mathrm{pH}$ 6.8) containing $10 \mathrm{mM}$ ascorbic acid and $0.5 \%$ polyvinylpyrrolidone with the aid of a magnetic stirrer for $1 \mathrm{~h}$. The crude extract samples were centrifuged at $30000 \mathrm{~g}$ for $20 \mathrm{~min}$ at $4^{\circ} \mathrm{C}$. Solid ammonium sulphate (NH4)2SO4 was added to the supernatant to obtain 30 and $80 \%$ (NH4)2SO4 saturation, respectively. After $1 \mathrm{~h}$, the precipitated proteins for each stage were separated by centrifugation at $30000 \mathrm{~g}$ for $30 \mathrm{~min}$. The precipitate was redissolved in a small volume of distilled water and dialyzed at $4^{\circ} \mathrm{C}$ against distilled water for $24 \mathrm{~h}$ with 4 changes of the water during dialysis. The dialysate was applied to a column $(2.5 \mathrm{~cm} \times 30$ $\mathrm{cm}$ ) filled with DEAE-cellulose, balanced with $10 \mathrm{mM}$ phosphate buffer, $\mathrm{pH}$ 6.8. In order to remove non adsorbed fractions the column was washed with $200 \mathrm{~mL}$ of the same buffer at the flow rate of $0.5 \mathrm{~mL} / \mathrm{min}$. Then, a linear gradient of phosphate buffer concentration from 20 to $180 \mathrm{mM}$ was applied. $5 \mathrm{~mL}$ fractions were collected in which the protein level and diphenol oxidase activity towards catechol as substrate were monitored. The fractions which showed diphenol oxidase activity were combined and were used as enzyme source in the following experiments. Protein concentration measured by lowry method.[ Lowry et al., 1951].

\subsection{Diphenol oxidase Assay}

Enzymatic activity was determined by measuring the increase in absorbance at $420 \mathrm{~nm}$ for catechol with a spectrophotometer (6305 JENWAY). The sample cuvette contained $3 \mathrm{ml}$ of substrate catechol in constant concentrations and in presence of different concentration of L-glycine or L-cysteine, prepared in the phosphate buffer. Assays were carried out by addition of $200 \mu \mathrm{l}$ of extracts to the sample cuvette, and changes in absorbance $420 \mathrm{~nm}$ were recorded. The reference cuvette contained just $3 \mathrm{ml}$ of substrate solution. Polyphenol oxidase activity was determined by measuring the amount of quinone produced, using an extinction coefficient of $2450 \mathrm{M}^{-1} \mathrm{~cm}^{-1}$ for catechol. Enzyme activity was calculated from the linear portion of the curve. One unit of diphenol oxidase activity was defined as the amount of enzyme that produces 1 micromole of quinone per minute. Assays were carried out at room temperature and results are the averages of at least three assays. 


\subsection{Inhibition of Diphenol oxidase Activity by L-glycine Concentration and pH}

Inhibition of Diphenol oxidase activity was conducted in a disposable cuvette containing $3 \mathrm{~mL}$ of the standard reaction mixture. The concentration of L-glycine was $0,0.2$, $0.4,0.6,0.9,1.2,1.4,1.8$ and $2 \mathrm{M}$ in an phosphate buffered reaction mixture with $\mathrm{pH}$ of 6.7 and 8, and Diphenol oxidase activity for the oxidation of catechol at a final concentration of 15 and $45 \mathrm{mM}$ was determined at $\mathrm{pH} 6.7$ and 8 respectively. This concentration for Lcysteine was $0,0.2,0.4,0.8,1,2,3,5,8$ and $16 \mathrm{M}$ in an phosphate buffered reaction mixture with $\mathrm{pH}$ of 6.7 and 8 .

\subsection{Inhibition of Diphenol oxidase Activity by L-cysteine Concentration and pH}

Inhibition of Diphenol oxidase activity was conducted in a disposable cuvette containing $3 \mathrm{~mL}$ of the standard reaction mixture. The final concentration of L-cysteine was 0.35 and $1.2 \mathrm{M}$ in an phosphate buffered reaction mixture with $\mathrm{pH}$ of 6.7 and 0.33 and $1.2 \mathrm{M}$ in an phosphate buffered reaction mixture with $\mathrm{pH}$ of 8 , and Diphenol oxidase activity for the oxidation of catechol at a final concentration of 15 and $45 \mathrm{mM}$ was determined at $\mathrm{pH} 6.7$ and 8 , respectively.

\subsection{Kinetic Study}

Various concentrations of catechol $(25-50 \mathrm{mM})$ and L-cysteine $(0.0,0.35$ and $1.2 \mathrm{mM})$ were prepared in $0.1 \mathrm{M}$ phosphate buffer ( $\mathrm{pH}$ 6.7). These various concentrations for catechol were 5, 7, 10, 15 and $20 \mathrm{mM}$ and for L-cysteine were $0.0,0.33$ and $1.2 \mathrm{M}$ at $\mathrm{pH} 8$. Various concentrations of catechol $(7,10,15$ and $20 \mathrm{mM})$ and L-glycine $(0.0,0.74$ and $1.2 \mathrm{M})$ were prepared in $0.1 \mathrm{M}$ phosphate buffer $(\mathrm{pH}$ 6.7). These various concentrations for catechol at $\mathrm{pH} 8$ were $8,10,12,15$ and $16 \mathrm{mM}$ and for inhibitor of L-glycine were $0.0,0.74$ and $1.2 \mathrm{M}$. The reaction mixture and Diphenol oxidase activity assay were the same as those for the standard reaction. The inhibition kinetics of L-glycine and L-cysteine on Diphenol oxidase activity were determined by Lineweaver-Burk plots [Marangoni., 2002].

\subsection{Preincubation of L-glycine with Diphenol oxidase or catechol.}

Preincubation of L-glycine with Diphenol oxidase was performed by mixing a series of L-glycine solutions $(0.4,0.7$ and $1.2 \mathrm{mM})$ prepared in $0.1 \mathrm{M}$ phosphate buffer $(\mathrm{pH} 8)$ with diphenol oxidase extract in a cuvette held at $25{ }^{\circ} \mathrm{C}$ for $0,1,2$, 4, and $5 \mathrm{~min}$. The reaction was initiated by adding $45 \mathrm{mM}$ catechol to the L-glycine and Diphenol oxidase mixture after the tested incubation time. For the preincubation study between L-glycine and catechol, $1 \mathrm{M} \mathrm{L}$-glycine and $15 \mathrm{mM}$ catechol were mixed and held at $25{ }^{\circ} \mathrm{C}$ for $5 \mathrm{~min}$. The reaction was initiated by adding Diphenol oxidase to the mixture, and the diphenol oxidase activity was determined following the same procedure as described above.

\subsection{Preincubation of L-cysteine with diphenol oxidase or catechol.}

Preincubation of L-cysteine with Diphenol oxidase was performed by mixing a series of L-cysteine solutions $(0.4,0.7$ and $1 \mathrm{M}$ ) prepared in $0.1 \mathrm{M}$ phosphate buffer ( $\mathrm{pH}$ 6.7) with Diphenol oxidase extract in a cuvette held at $25{ }^{\circ} \mathrm{C}$ for $0,1,2,4$, and $5 \mathrm{~min}$. The reaction was initiated by adding $15 \mathrm{mM}$ catechol to the L-cysteine and Diphenol oxidase mixture 
after the tested incubation time. For the preincubation study between L-cysteine and catechol, $5 \mathrm{M} \mathrm{L}$-cysteine and $45 \mathrm{mM}$ catechol were mixed and held at $25{ }^{\circ} \mathrm{C}$ for $5 \mathrm{~min}$. The reaction was initiated by adding Diphenol oxidase to the mixture, and the Diphenol oxidase activity was determined following the same procedure as described above.

\section{RESULTS AND DISCUSSION}

\subsection{Effect of L-glycine and L-cysteine acid on Diphenol oxidase activity in strawberry extract}

L-glycine and L-cysteine inhibited the Diphenol oxidase activity detectable with catechol as substrate. The concentration of L-glycine inhibiting Diphenol oxidase activity by $50 \%$ (IC50) was 0.5 and $0.4 \mathrm{mM}$ at $\mathrm{pH} 6.7$ and 8, respectively (Figure 1). IC50 for Lcysteine inhibiting Diphenol oxidase activity was 0.4 at pH 6.7 and 0.5 at $\mathrm{pH} 8$ (Table 1).

Table 1. Effect of L-glycine and cysteine on the DIPHENOL OXIDASE activity at pH 6.7 and 8.

\begin{tabular}{|c|c|c|c|c|}
\hline \multirow{6}{*}{$\begin{array}{l}\text { Substrate } \\
\text { (catechol) }\end{array}$} & \multirow{3}{*}{ pH 6.7} & Inhibitor & IC50 (M) & $\begin{array}{c}\text { Type of } \\
\text { inhibition }\end{array}$ \\
\hline & & Glycine & 0.3 & Uncompetetive \\
\hline & & Cysteine & 0.35 & Uncompettive \\
\hline & \multirow{3}{*}{$\mathrm{pH} 8$} & Inhibitor & $\operatorname{IC} 50(\mathrm{M})$ & $\begin{array}{c}\text { Type of } \\
\text { inhibition }\end{array}$ \\
\hline & & Glycine & 0.45 & competetive \\
\hline & & Cysteine & 0.4 & Competetive \\
\hline
\end{tabular}

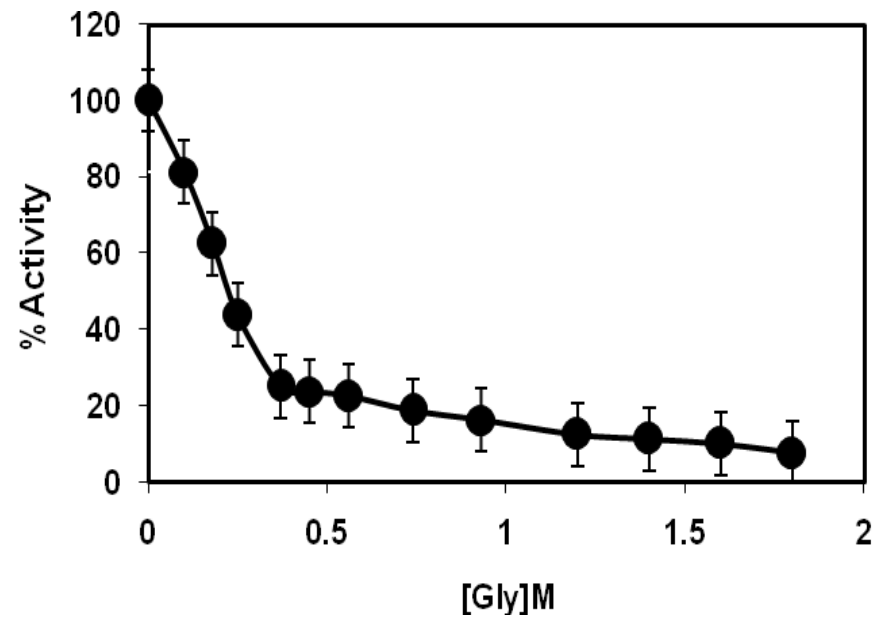

Figure 1. L-glycine -mediated inhibition of iphenol oxidase activity as reflected by the oxidation of catechol. 


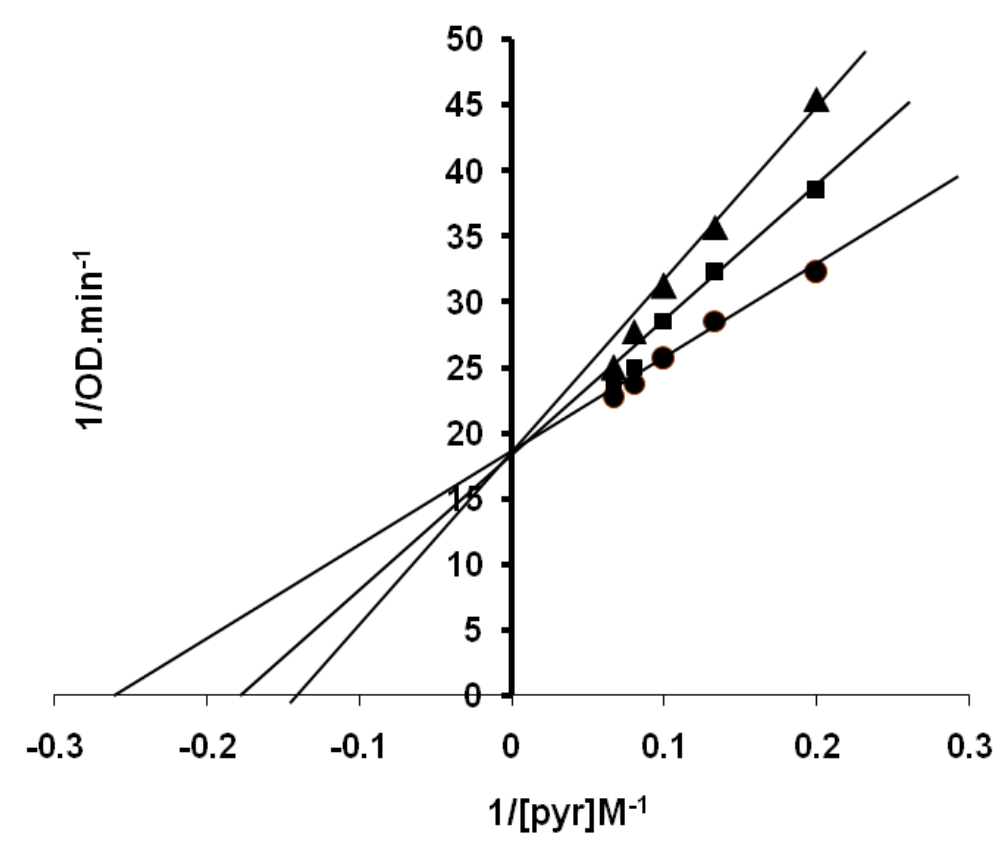

Figure 2. Inverse plots obtained when catechol oxidation was assayed in the presence of different Lglycine concentrations.

\subsection{Inhibition Kinetic of L-glycine on DIPHENOL OXIDASE Activity at pH 6.7 and 8}

Inhibition of DIPHENOL OXIDASE by L-glycine was determined in the presence of different concentrations of L-glycine for three fixed concentrations of catechol at $\mathrm{pH} 6.7$ and pH 8 (Figure 2). Lineweaver burk plots used to analyze inhibition kinetics show that the extrapolated lines for $1 / V$ versus $1 /$ [catechol] are parallel and don't intersect each other near or on the $y$ and $x$-axis, indicating that L-glycine is a uncompetetive type inhibitor. L-glycine as a uncompetetive inhibitor are thought to bind the the DIPHENOL OXIDASE-catechol complex and not the diphenol oxidase. The effect of L-glycine is to decrease both Vmax and $\mathrm{Km}$. A lower $\mathrm{Km}$ corresponds to a higher affinity. The presence of L-glycine as uncompetitive inhibitor increases the affinity of the enzyme for the catechol. An 5-min preincubation of diphenol oxidase with $0.5 \mathrm{M}$ L-glycine resulted in a $35 \%$ loss in DIPHENOL OXIDASE activity compared to control. Interestingly, preincubation of Lglycine with catechol for $5 \mathrm{~min}$ resulted in no additional loss of DIPHENOL OXIDASE activity compared to that without incubation (Figure 3). This finding suggests that L-glycine inhibits DIPHENOL OXIDASE activity by acting directly on the diphenol oxidase-substrate rather than on the enzyme.

\subsection{Inhibition Kinetic of L-cysteine on diphenol oxidase Activity at pH 8}

Inhibition of DIPHENOL OXIDASE by L-cysteine was determined in the presence of different concentrations of L-cysteine for three fixed concentrations of catechol at $\mathrm{pH}$ 8.0. Lineweaver burk plots used to analyze inhibition kinetics show that the extrapolated lines for $1 / V$ versus $1 /[$ catechol] intersect each other on the $y$-axis, indicating that L-cysteine is a 
competetive type inhibitor. L-cysteine as a competetive inhibitor can bind at the active site of the enzyme to form an diphenol oxidase-L-cysteine complex. L-cysteine blocks the active site, and catechol as substrate cannot bind until the inhibitor dissociates. Since, L-cysteine and catechol compete for the same site, raising the catechol concentration can eventually overcome the L-cysteine, and Vmax can be achieved, but L-cysteine raises $\mathrm{Km}$, indicating that the affinity of diphenol oxidase for catechol is lower in the presence of L-cysteine. To further investigate whether the inhibition of diphenol oxidase activity by L-cysteine is attributable to the inhibitor's effect on diphenol oxidase, the substrate, or both, preincubation of L-cysteine with diphenol oxidase or catechol was carried out before the inhibition reaction started.

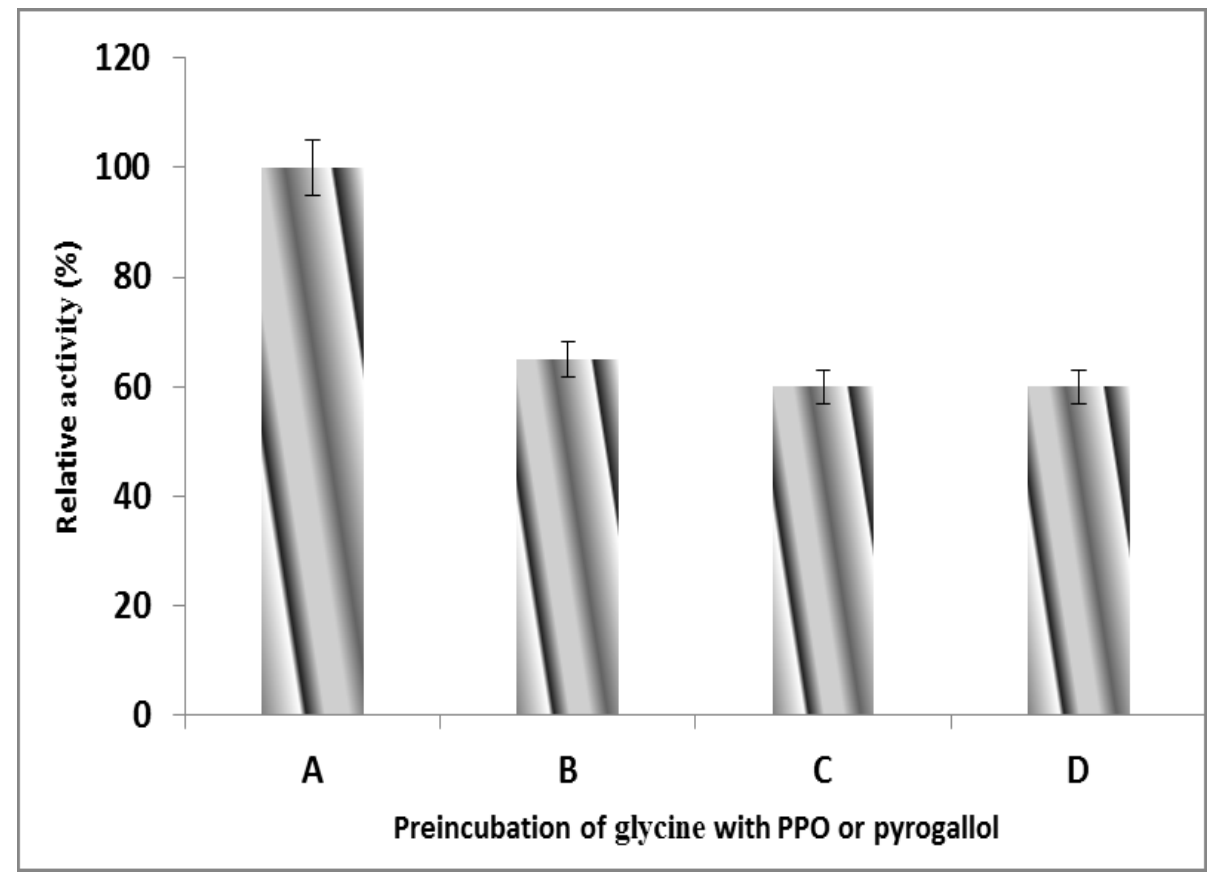

Figure 3. Effects of preincubation of glycine with diphenol oxidase or catechol on the inhibition of strawberry diphenol oxidase activity at $\mathrm{pH}$ 6.7. diphenol oxidase activity for the oxidation of catechol was determined in a standard reaction mixture buffered with $0.1 \mathrm{M}$ phosphate buffer, after preincubation for $5 \mathrm{~min}$ by mixing either diphenol oxidase or catechol (15 $\mathrm{mM}$ final concentration) with $0.5 \mathrm{M}$ glycine. Activities were expressed as percent relative activity to that determined without glycine or preincubation: no glycine or preincubation (A); $0.5 \mathrm{M}$ glycine, no preincubation (B); preincubation of glycine with catechol (C); preincubation of glycine with diphenol oxidase (D).

The vertical bars represent the standard errors of three replicates. An 5-min preincubation of diphenol oxidase with $1 \mathrm{M}$ L-cysteine resulted in a $60 \%$ loss in diphenol oxidase activity compared to control (without inhibitor) (Figure not shown). Interestingly, preincubation of cystein with catechol for 5 min resulted in no additional loss of diphenol oxidase activity compared to that without incubation. This finding suggests that L-cysteine inhibits diphenol oxidase activity by acting directly on the diphenol oxidase rather than on the substrate. 


\subsection{Inhibition Kinetic of L-cysteine on DIPHENOL OXIDASE Activity at pH 6.7}

Inhibition of diphenol oxidase by L-cysteine was determined in the presence of different concentrations of L-cysteine for three fixed concentrations of catechol at $\mathrm{pH} 6.7$ (not shown). Lineweaver burk plots used to analyze inhibition kinetics show that the extrapolated lines for $1 / V$ versus $1 /$ [catechol] intersect each other on the $x$-axis, indicating that L-cysteine is a noncompetetive type inhibitor. L-cysteine as a noncompetetive inhibitor can bind at an allosteric site on the diphenol oxidase and leave the active site unblocked. Catechol as substrate has an identical affinity for both the L-cysteine diphenol oxidase complex and diphenol oxidase. In presence of L-cysteine as noncompetitive inhibitor of diphenol oxidase, the $\mathrm{Km}$ value is unchanged $(100 \mathrm{mM})$, while $\mathrm{V}_{\max }$ is decreased from 0.2 to $0.09 \Delta \mathrm{A} \mathrm{min}{ }^{-1}$. An 5-min preincubation of diphenol oxidase with $1 \mathrm{M} \mathrm{L}$-cysteine resulted in a $70 \%$ loss in diphenol oxidase activity compared to control. Interestingly, preincubation of cystein with catechol for $5 \mathrm{~min}$ resulted in no additional loss of diphenol oxidase activity compared to that without incubation (Figure 4). This finding suggests that L-cysteine inhibits diphenol oxidase activity by acting directly on the diphenol oxidase rather than on the substrate.

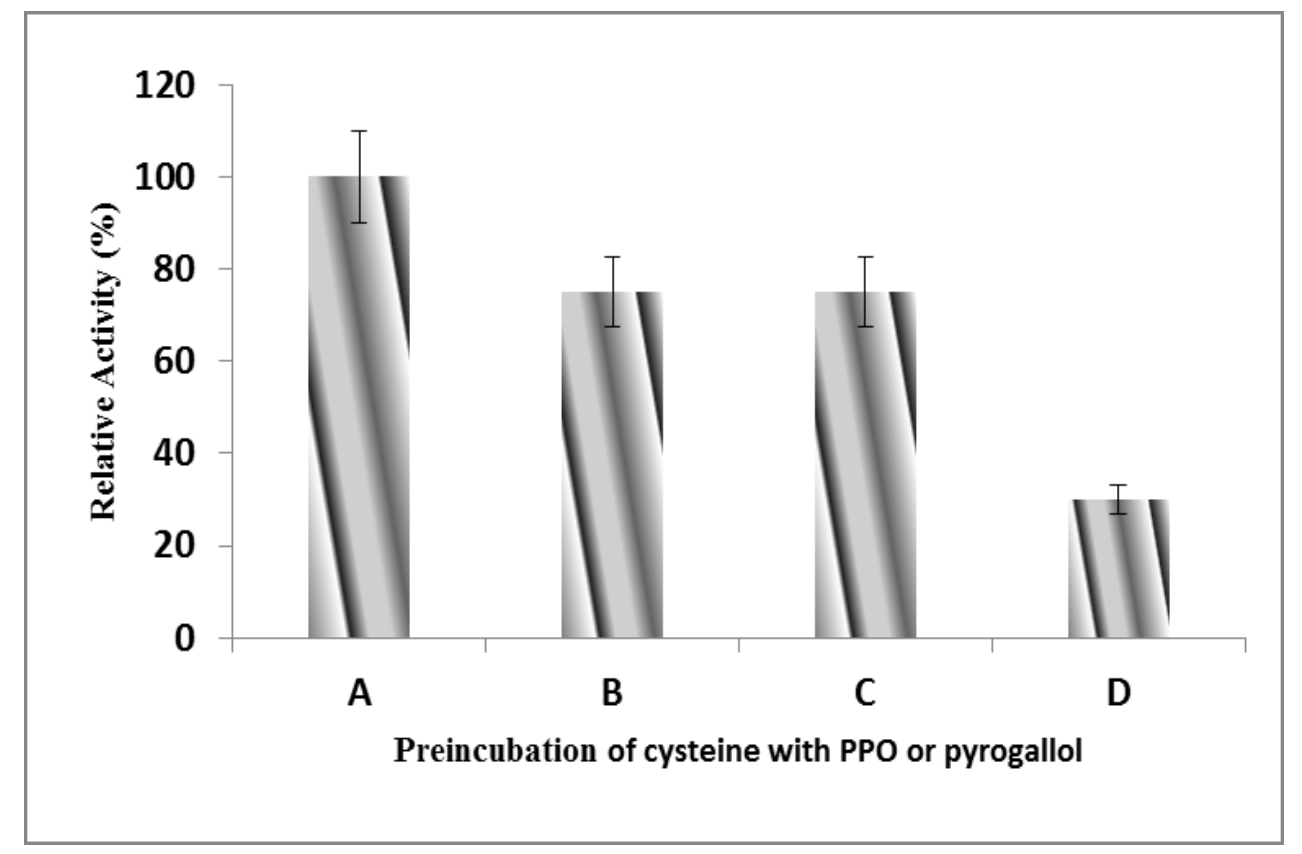

Figure 4. Effects of preincubation of cysteine with diphenol oxidase or catechol on the inhibition of strawberry diphenol oxidase activity at $\mathrm{pH}$ 6.7. Diphenol oxidase activity for the oxidation of catechol was determined in a standard reaction mixture buffered with $0.1 \mathrm{M}$ phosphate buffer, after preincubation for $5 \mathrm{~min}$ by mixing either diphenol oxidase or catechol (15 $\mathrm{mM}$ final concentration) with $1 \mathrm{M}$ cysteine. Activities were expressed as percent relative activity to that determined without preincubation: no cysteine or preincubation (A); 1M cysteine, no preincubation (B); preincubation of cysteine with catechol (C); preincubation of cysteine with diphenol oxidase (D). The vertical bars represent the standard errors of three replicates. 
Table 2. Kinetics parameters for the diphenol oxidase activity at $\mathrm{pH} 6.7$ and $\mathrm{pH} 8$.

\begin{tabular}{|c|c|c|c|c|c|}
\hline $\mathrm{pH}$ & Substrate & Inhibitors & $\begin{array}{c}\mathrm{V}_{\max } \\
\text { (Unit/ } \\
\text { mg.protein) }\end{array}$ & $\begin{array}{c}\mathrm{Km} \\
(\mathrm{mM})\end{array}$ & $\begin{array}{l}\text { Catalytic } \\
\text { efficiency }\end{array}$ \\
\hline \multirow{3}{*}{6} & \multirow{3}{*}{ Catechol } & --------------- & 112 & 22 & 5 \\
\hline & & Glycine $(0.74 \mathrm{M})$ & 45 & 19 & 2.3 \\
\hline & & Glycine(1.4 M) & 36 & 17 & 2.1 \\
\hline \multirow{3}{*}{7} & \multirow{3}{*}{ Catechol } & ------------- & 145 & 9 & 16.1 \\
\hline & & Glycine $(0.7 \mathrm{M})$ & 88 & 8.2 & 10.7 \\
\hline & & Glycine $(1.25 \mathrm{M})$ & 62 & 6.8 & 9.1 \\
\hline \multirow{3}{*}{6} & \multirow{3}{*}{ Catechol } & ------------- & 112 & 22 & 5 \\
\hline & & Cysteine $(0.35 \mathrm{M})$ & 58 & 20 & 2.9 \\
\hline & & Cysteine $(1.2 \mathrm{M})$ & 32 & 19.5 & 1.6 \\
\hline \multirow{3}{*}{7} & \multirow{3}{*}{ Catechol } & -------------- & 145 & 9 & 16.1 \\
\hline & & Cysteine $(0.35 \mathrm{M})$ & 78 & 7.8 & 10 \\
\hline & & Cysteine (1.6M) & 35 & 7.5 & 4.6 \\
\hline
\end{tabular}

\subsection{Kinetic parameters of DIPHENOL OXIDASE activity in strawberry extract in presence of inhibitors}

The Michaelis-Menten constant $(\mathrm{Km})$ and maximum rate $\left(\mathrm{V}_{\max }\right)$ values for diphenol oxidase activity in strawberry extract were determined by performing activity assays at $\mathrm{pH}$ 6.7 and $\mathrm{pH} 8$, in the presence of extract aliquots and various concentrations of either catechol as substrate and various concentrations of L-glycine and L-cysteine as inhibitors. The rate of catechol oxidation to its corresponding o-quinone was measured by monitoring the absorbance increase at $420 \mathrm{~nm}$ in a $3-\mathrm{ml}$ reaction mixture containing $0.75 \mathrm{mg}$ extract protein. The maximum rate $\left(\mathrm{V}_{\max }\right)$ for catechol oxidation at $\mathrm{pH} 6.7$ and in absence of Lglycine was $0.25 \Delta \mathrm{A} \mathrm{min}{ }^{-1}$, with a $\mathrm{Km}$ of $25 \mathrm{mM}$. The catalytic efficiency calculated per milligram protein in the extract was 1.8 units $\mathrm{mg}^{-1}$ prot $\mathrm{mM}^{-1}$ (Table 2). The maximum rate $\left(\mathrm{V}_{\max }\right)$ and $\mathrm{Km}$ for catechol oxidation at $\mathrm{pH} 6.7$ and in presence of L-glycine (1.4M) was $0.09 \Delta \mathrm{A} \mathrm{min}{ }^{-1}$ and $10 \mathrm{mM}$, but catalytic efficiency decreased to 1.3 units $\mathrm{mg}^{-1}$ prot $\mathrm{mM}^{-1}$. The maximum rate $\left(\mathrm{V}_{\max }\right)$ for catechol oxidation at $\mathrm{pH} 8$ and in absence of L-glycine was $0.09 \Delta \mathrm{A} \mathrm{min}{ }^{-1}$, with a Km of $3.5 \mathrm{mM}$. $\mathrm{V}_{\max }$ in presence of L-glycine $(1.25 \mathrm{M})$ decreased and reached to $0.07 \Delta \mathrm{A} \mathrm{min}{ }^{-1}$ and $\mathrm{Km}$ decreased to $3.1 \mathrm{mM}$. Catalytic efficiency at $\mathrm{pH} 8$ in presence of L-glycine decreased from 4.6 to 3.8 units $\mathrm{mg}^{-1}$ prot $\mathrm{mM}^{-1}$. Data in table 2 shows that catalytic efficiency decreased for catechol oxidation in presence of L-glycine and Lcysteine at $\mathrm{pH} 6.7$ and $\mathrm{pH} 8$.

\section{CONCLUSION}

This study demonstrates that L-glycine and L-cysteine exhibit, strong inhibition of strawberry diphenol oxidase activity. The inhibition of diphenol oxidase activity is $\mathrm{pH}$ and 
inhibitor dependent. Kinetic studies via lineweaver-Burk plots indicate that L-glycine is a uncompetetive inhibitor and L-cysteine is competitive and noncompetitive inhibitor of partial purified diphenol oxidase activity. As reported for other plants [Ho K-K., 1999], [ Escribano et al., 2002], multiple isoforms of diphenol oxidase were detected in saffron [Saeidian et al., 2007], so we can conclude that diphenol oxidase in strawberry (Crataegus spp) maybe have two isoforms, because of different kinetic properties at $\mathrm{pH} 6.7$ and 8 .

\section{Acknowledgment}

This work was done in part by the University of Payame Noor, and was done in exploratory laboratory of biochemistry in payame noor of saghez (Kurdistan).

\section{References}

[1] Broothaerts, W. Mcpherson, J. B. Li, B. Randall, E. Lane, W.D and Wierma, P.A.. J. Agric. Food Chem (2000). 48: 5924-5928.

[2] Constabel, C.P. Lynn, Y. Patton, J.J. Christopher, M.E. Plant Physiol. (2000) 124, 285-295.

[3] Escribano, J. Gandı'a-Herrero, F. Caballero, N. Pedreño, MA. J Agric Food Chem (2002) 50:6123-6129

[4] Espin, J.C. Garcia-Ruiz, P.A. Tudela, J. Varon, R. and Garcia-Canovas, F. J. Agric. Food Chem. (1998) 46 (8): 2968-2975.

[5] Ho K-K., Plant Physiol Biochem (1999)37:841-848.

[6] Lowry, O.H. Rosebrough, N.J. Farr, A.L. and Randall, R.J. J. Biol. Chem. (1951) 193: 265-27.

[7] Marangoni, A. G. Wiley: Hoboken, NJ , (2002) pp 61-65.

[8] Mohammadi, M. Kazemi, H. Plant Sci. (2002)162, 491-498.

[9] Robb, D.A. CRC Press. Boca Raton, FL. In Contie R (Ed) (1984) 2: 207-241.

[10] Ryan, C.A. Biochim. Biophys. Acta . (2000), 1477, 112-121.

[11] Saeidian, S. Keyhani, E. and Keihani, J. Acta Physiol Plant. (2007) 29: 463-471.

[12] Saeidian, S. Keyhani, E. and Keihani, J. J. Agric. Food Chem. (2007) 55(9): 37133719.

[13] Sanchez-Amat, A. and Solano, F. Biochem .Biophys. Res. Comm. (1997) 240: $787-$ 792.

[14] Trebst, A. Depka, B. Photosynth. Res. (1995)46, 41-44.

[15] Van Gelder, C.W. Flurkey, W.H. and Wichers, H.J. Phytochemistry (1997) 45: 1309-23. 